\title{
Factors Associated with Relapse of Psychosis among Patients Attending Tertiary Hospital of Tamil Nadu, India
}

\author{
Shobha Laxmi Bajracharya \\ *Associate Professor, Patan Academy of Health Sciences, School of Nursing and Midwifery, Lalitpur Nursing Campus, Sanepa, Lalitpur, Nepal. \\ DOI: 10.29322/IJSRP.11.09.2021.p11759 \\ http://dx.doi.org/10.29322/IJSRP.11.09.2021.p11759
}

\begin{abstract}
Introduction: Psychotic illness constitutes the highest burden of disease in the world with relapse being one of the most pertinent barriers to recovery and rehabilitation. Relapse leads disability among the psychotic patients; thus, it is an issue of global concern. This study aimed to analyse the factors associated with relapse in patients with psychosis.

Methods: Hospital-based case control study was conducted at a tertiary hospital of Tamil Nadu, India. Purposive sampling technique was used to select the sample for both the cases (70) and controls (70) in a 1:1 ratio. Data were collected through face-toface interview using Drug Attitude inventory, Presumptive Stressful Life Events Scale and Multi-dimensional Scale of Perceived Social Support. Descriptive and inferential statistics (Pearson Chi-square and odds ratio) were used for analyzing the data. $P$ value was set at 0.05 .
\end{abstract}

Results: Researcher found that there were significant differences in drug attitude, perceived stressful life events and social support in between cases and controls, $p=<0.05$. Favourable attitude towards drug intake $(\mathrm{OR}=.132,95 \% \mathrm{CI}=.059-.294)$, more stressful life events $(\mathrm{OR}=2.803,95 \% \mathrm{CI}=.1 .393-5.641)$ and high social support $(\mathrm{OR}=.398,95 \% \mathrm{CI}=.187-.850)$ in between cases and controls were the significant factors of the relapse in patients with psychosis.

Conclusion: Based on the findings of this study, it can be concluded that the unfavourable attitude towards drug intake, more stressful life and low to moderate social support are the significant factors associated with relapse of psychosis suggesting that there is need to take consideration in order to prevent relapse in psychosis. Psychiatric nurse plays an important role in relapse prevention.

Index Terms- Case-control study, drug attitude, perceived stressful life events, psychosis, relapse, social support

\section{INTRODUCTION}

$\mathrm{P}$ sychosis is a severe type of mental illness in which functions of the body and mind are severely disturbed, lacks touch with reality and unaware of own illness and can refuse to take treatment ${ }^{[1]}$. Relapse is very common in psychotic disorders, and it leads to increase disability among the psychotic patients ${ }^{[2]}$ and the effect of high relapse rate increases economic burden, high morbidity, high readmission rate and a high burden on the health care system and community services ${ }^{[3]}$. Thus, the relapse in psychosis is issues of global concern ${ }^{[4]}$.

Relapse refers to a return of symptoms after a period of improvement or recovery ${ }^{[5]}$. Relapse may be expressed in terms of functionality which needs greater interventions ${ }^{[6]}$. Globally over 20 million people are affected by schizophrenia ${ }^{[7]}$, with relapse rate of $28.0 \%, 43 \%$ and $54 \%$ have been reported during the first, second and the third year respectively ${ }^{[8]}$ resulting in increased functional, social, and occupational disability [9]. Relapse in patients with psychosis is a major challenge in the field of mental health service worldwide. ${ }^{[10]}$.

Clients with psychotic disorders are at great risk for relapse and re-hospitalization. The risk is magnified by poor adherence to medications and refusal to accept optimal treatment as prescribed ${ }^{[11]}$. Individuals with psychotic disorders fails to take prescribed medications are one of the most serious problems in psychiatric care. Failure to take medications often leads to relapses, rehospitalization and episodes of violence ${ }^{[12]}$. The response to medication tends to decrease with each relapse and the individual becomes more disabled, requiring more support. With each relapse, patients lose their abilities to take care of themselves and enjoy their lives. ${ }^{[13]}$ Medication side effects are reason for medication non-adherence is in fact a less important reason compared to the other factors cited ${ }^{[12]}$.Poor treatment compliance, stressful life events and poor social support are the factors associated with relapse of psychotic disorder. ${ }^{[14,15]}$

In a study conducted on impact of life events on the relapse of schizophrenic patients revealed that more than half of the patients had $30 \%$ chance of relapse related to the exposure to recent life events. ${ }^{[16]}$ It has been suggested that stressful life events and subsequent psychotic illness. Thus, stressful life events are positively related with subsequent psychotic illness. ${ }^{[17]}$. In a study conducted on relationships between social support and life events in the relapse of 42 schizophrenic patients found that the patients contented with low social integration in the 9 months of follow up had a higher relapse rate ${ }^{[18]}$.

A large study conducted in ten psychiatric hospitals of China among 876 schizophrenic outpatients aged 18 to 65 years showed that $33.4 \%$ had at least one relapse within one year after discharge and $18.8 \%$ were re-hospitalized. The most important factor contributing to relapse was poor medication adherence $(50.7 \%), 30 \%$ had negative attitude towards medication. Among non-adherent patients $37.9 \%$ had a relapse rate was 2.5 -fold higher than adherent patients (54.5\% versus $20.7 \%$, p<.001). Relapse 
with non-adherence to medication $(\mathrm{OR}=4.602$, 95\% CI 3.410$6.211)^{[19]}$.A study conducted at national institute of mental health and neurosciences, Bangalore, India in 2004 for 1 year with the first episode of 57 diagnosed ATPDs, the relapse was recorded in $47.4 \%$ and $54.4 \%$ at the end of first and second year respectively ${ }^{[20]}$.

Relapse in the early phase of psychosis is associated with increased probability of further relapse and persisting symptoms. Early relapse prevention is therefore most important in patients with psychosis to prevent further damage and deterioration of patient functioning and mental health ${ }^{[21]}$.It is important responsibility of the psychiatric nurse to educate patients and their families about these aspects to prevent relapse in a patient with psychosis ${ }^{[13]}$.Hence, there is a need for a scientific study to explore the relapse factors. Finding out the relapse factors would help the psychiatric nurse to educate patients and their families with a view to prevent relapse in patients, which will enhance a better quality of life. Therefore, the aim of this study was to analyse the factors associated with relapse in patients with psychosis among patients with psychosis.

\section{MATERIALS AND METHODS}

This study was a hospital-based case control design study carried out on factors associated with relapse in psychosis attending tertiary hospital of Tamil Nadu, India among adult inpatients and outpatients with psychosis. The study was conducted in Mental Health Centre, Christian Medical College, Vellore. The Mental Health Centre provides treatment for all varieties of mental and emotional disorders. It provides all modern forms of psychiatric treatment i.e., Drug Therapy, Electro Convulsive Therapy (ECT), Psychological Therapies and Group Therapy. The purposive sampling technique was used to collect data from relapse and non-relapse groups of psychotic patients. As the case control ratio was kept 1:1, the final sample consisted of 140 psychotic patients; 70 were with relapse symptoms included in case group and 70 patients were with no relapse symptoms at least for the past six months in the control group.

\section{Selection criteria for cases and controls}

Patients with psychosis who were diagnosed as schizophrenia/mania with psychosis/ depression with psychosis, above 18 years of age, inpatient or outpatient with a history of at least one episode of psychosis in past and with relapse symptoms who were cooperative and willing to be interviewed and could converse in English/Hindi/Tamil were selected as cases.

Patients with psychosis who were diagnosed as schizophrenia/mania with psychosis/ depression with psychosis, above 18 years of age, inpatient or outpatient with a history of psychosis without relapse symptoms at least within the past six months and on regular treatment who were cooperative and willing to be interviewed and could converse in English/Hindi/Tamil were selected as controls.

Patients with mental retardation, psychosis other than schizophrenia, mania with psychosis, depression with psychosis and organic psychosis excluded.

\section{Data collection instruments}

This publication is licensed under Creative Commons Attribution CC BY.

http://dx.doi.org/10.29322/IJSRP.11.09.2021.p11759
Data collection instrument used for this study was consisted of four parts:

Part-I consisted of self-developed structured questionnaire to assess socio-demographic and clinical characteristics that included age, gender, marital status, educational status, occupation, family income, living, locality, state of residence, diagnosis, age of onset of illness and duration of illness.

Part-II consisted of Drug Attitude Inventory (DAI10). ${ }^{[22]}$ DAI-10 is a brief drug attitude standardized; validated screening scale which aimed to gain understanding of what people think about medications and what experiences people have of them.DAI-10is considered to be the best predictor of poor adherence in psychosis. The test-retest reliability of DAI-10 was (0.79) [23]. DAI-10 is an easy-to-use instrument seemingly assessing a unique clinical dimension relevant to non-adherence. DAI-10 might be preferred for its simplicity and good psychometric properties. This scale consists of a total of 10 items; six items were scored as true and four scored as false. All the correct responses were scored as " 1 " and all incorrect responses were scored as " 0 ". The higher score on DAI scale indicated good compliance. ${ }^{\text {[2] }}$

Part-III consisted of Presumptive Stressful Life Events Scale (PSLES). ${ }^{[25]}$ PSLES is a new standardized stressful life events scale developed as suitable scale for assessing stressful life events for Indian patients in 1981 by using open-ended questionnaire on a sample of 200 adult subjects. It was based on fruitful collaborations of Holmes and Rahe, who believed that some kind of a list of commonly encountered stressors would be more useful than the relatively unregulated process of taking an unstructured history. After considerable research, they developed a list of 51 life events, ranging in severity from death of a spouse to going on a pleasure trip/pilgrimage. For each stressful life events item, the mean stress score is given.

Part-IV consisted of Multi-dimensional Scale of Perceived Social Support (MSPSS). ${ }^{[26]}$ MSPSS is a standardized, brief, and free to use research tool designed to measure perceptions of support from 3 sources: Family, Friends, and Significant Others. The scale is comprised of a total of 12 items, with 4 items for each subscale. This is a 7-point rating scale, which ranges from one (very strongly disagree) to seven (very strongly agree). The minimum score is 12 and the maximum is 84 . Higher the score shows better social support. Across many studies, the MSPSS has shown to have good to excellent internal consistency and testretest reliability with a Cronbach's alpha of 0.81 to 0.98 in nonclinical samples, and 0.92 to 0.94 in clinical samples. ${ }^{[27]}$ For categorization, the Significant Other Subscale sum across items 1, 2, 5, \& 10; Family Subscale sum across items 3, 4, 8, \& 11; Friends Subscale sum across items $6,7,9, \& 12$, and then divide by 4 in each of the sum. For total scale sum across all 12 items, then divide by 12 . Any mean scale score ranging from 1 to 2.9 could be considered low support; a score of 3 to 5 could be considered moderate support; a score from 5.1 to 7 could be considered high support.

All the above questionnaires were translated into Tamil and Hindi languages were translated back and tested during pilot study conducted with $20 \%$ of the proposed sample size and found suitable to use in the Indian setting.

Data were collected through face-to-face interview using printed questionnaires in English/Tamil/Hindi according to the 
respondents speaking language. The investigator used an interpreter throughout the study to administer the Tamil translated questionnaire to the respondents who speak Tamil and investigator rated their responses as per the interpreter. English and Hindi speaking respondents were interviewed by the investigator herself. All the respondents who fulfilled the inclusion criteria were included in the study. The total of 140 (equal number of relapse 70 and non-relapse 70) were interviewed from inpatient and outpatient department. It took about 45 minutes to complete the interview for each respondent.

\section{Ethical Consideration}

Psychotic patients were used as respondents of the study, so great care was exercised to protect their rights. Ethical consideration was maintained by obtaining written permission from the Dissertation Committee of College of Nursing, Christian Medical College, Vellore, South India for the study. Informed verbal consent was obtained prior to information collection after explaining the objective of the study to all the participants before collecting the data. Only interested participants were included in the study. Privacy of the participants was assured by collecting data in a separate room. Confidentiality of the respondents was maintained by coding and decoding and explaining the participants as the obtained data were used only for study purpose. Anonymity of the respondents was assured by not writing participants' name on the questionnaires and by keeping the collected information confidential.

\section{Statistical analysis:}

Data cleaning and analysis was done using Statistical Package of Social Sciences (SPPS) software version 16. Descriptive statistics was used to describe the sample sociodemographic and clinical characteristics. For analyzing the factors associated with relapse in patients with psychosis, inferential statistics (Pearson Chi-square) was used and to identify the odds, risk estimation was done. P-value was set at 0.05 .

\section{RESULTS}

Table 1: Socio-demographic information of Case and Control groups, $N=140$

\begin{tabular}{|c|c|c|c|c|}
\hline \multirow{2}{*}{ Characteristics } & \multicolumn{2}{|c|}{ Case Group n=70 } & \multicolumn{2}{|c|}{$\begin{array}{l}\text { Control Group } \\
\mathbf{n}=70\end{array}$} \\
\hline & No & $\%$ & No & $\%$ \\
\hline \multicolumn{5}{|l|}{ Age in years } \\
\hline$\leq 29$ & 30 & 42.9 & 23 & 32.9 \\
\hline $30-39$ & 24 & 34.3 & 23 & 32.9 \\
\hline $40-49$ & 9 & 12.9 & 14 & 20.0 \\
\hline $50-59$ & 5 & 7.1 & 9 & 12.9 \\
\hline$\geq 60$ & 2 & 2.9 & 1 & 1.4 \\
\hline Mean age \pm SD & \multicolumn{2}{|c|}{$33.51 \pm 10.94$} & \multicolumn{2}{|c|}{$35.79 \pm 11.12$} \\
\hline \multicolumn{5}{|l|}{ Gender } \\
\hline Male & 38 & 54.3 & 46 & 65.7 \\
\hline Female & 32 & 45.7 & 24 & 34.3 \\
\hline \multicolumn{5}{|l|}{ Marital status } \\
\hline Single & 32 & 45.7 & 27 & 38.6 \\
\hline Married & 34 & 48.6 & 37 & 52.9 \\
\hline Widowed/Separated & 4 & 5.7 & 6 & 8.6 \\
\hline \multicolumn{5}{|l|}{ Educational status } \\
\hline Illiterate & 8 & 11.4 & 9 & 12.9 \\
\hline Primary school & 12 & 17.1 & 21 & 30.0 \\
\hline Secondary school & 18 & 25.7 & 19 & 27.1 \\
\hline Higher Secondary school & 15 & 21.4 & 14 & 20.0 \\
\hline Graduate and above & 17 & 24.3 & 7 & 10.0 \\
\hline \multicolumn{5}{|l|}{ Occupation } \\
\hline Daily labour & 11 & 15.7 & 17 & 24.3 \\
\hline Homemaker & 14 & 20.0 & 19 & 27.1 \\
\hline Business & 3 & 4.3 & 2 & 2.9 \\
\hline Service & 9 & 12.8 & 6 & 8.6 \\
\hline No job & 23 & 32.8 & 21 & 30.0 \\
\hline Any other (student, retired) & 10 & 14.3 & 5 & 7.1 \\
\hline \multicolumn{5}{|c|}{ Family Income per month (in Rs.) } \\
\hline$<5000$ & 37 & 52.9 & 52 & 74.3 \\
\hline$\geq 5000$ & 33 & 47.1 & 18 & 25.7 \\
\hline
\end{tabular}




\begin{tabular}{|c|c|c|c|c|}
\hline Alone & 1 & 1.4 & 2 & 2.9 \\
\hline With family & 69 & 98.6 & 68 & 97.1 \\
\hline \multicolumn{5}{|l|}{ Locality } \\
\hline Rural & 34 & 48.6 & 33 & 47.1 \\
\hline Urban & 36 & 51.4 & 37 & 52.9 \\
\hline \multicolumn{5}{|l|}{ State } \\
\hline TamilNadu & 43 & 61.4 & 59 & 84.3 \\
\hline West Bengal & 12 & 17.1 & 2 & 2.9 \\
\hline Andhra Pradesh & 4 & 5.7 & 4 & 5.7 \\
\hline Karnataka & 2 & 2.9 & 4 & 5.7 \\
\hline $\begin{array}{l}\text { Others (Assam, Chhatisgath, Jharkand, Kerala, } \\
\text { Meghalaya, Orissa, Vihar) }\end{array}$ & 9 & 12.8 & 1 & 1.4 \\
\hline
\end{tabular}

Table 2: Clinical variables of Case and Control groups, $\mathrm{N}=140$

\begin{tabular}{|l|l|l|l|l|}
\hline \multirow{2}{*}{ Clinical variables } & \multicolumn{3}{l}{ Case Group n=70 } & $\begin{array}{l}\text { Control Group } \\
\text { n=70 }\end{array}$ \\
\cline { 2 - 5 } & No & $\mathbf{\%}$ & No & \% \\
\hline Diagnosis & 46 & 65.7 & 50 & 71.4 \\
\hline Schizophrenia & 14 & 20.0 & 12 & 17.1 \\
\hline Mania with psychosis & 10 & 14.3 & 8 & 11.4 \\
\hline Depression with psychosis & \multicolumn{5}{l|}{} \\
\hline Age of onset in years & 19 & 27.1 & 12 & 17.1 \\
\hline$\leq 20$ & 30 & 42.9 & 26 & 37.1 \\
\hline $21-30$ & 14 & 20.0 & 22 & 31.4 \\
\hline $31-40$ & 7 & 10.0 & 10 & 14.3 \\
\hline$>40$ & $26.73 \pm 9.04$ & $30.77 \pm 9.78$ \\
\hline Mean age of onset \pm SD & \multicolumn{5}{|l|}{} \\
\hline Duration of illness in years & 5 & 7.1 & 6 & 8.6 \\
\hline$<1$ & 33 & 47.1 & 44 & 62.9 \\
\hline $1-5$ & 18 & 25.7 & 11 & 15.7 \\
\hline $6-10$ & 14 & 20 & 9 & 12.8 \\
\hline$>10$ & $6.80 \pm 6.01$ & $5.00 \pm 5.43$ & \\
\hline Mean duration of illness \pm SD & \multicolumn{5}{|l|}{} \\
\hline
\end{tabular}

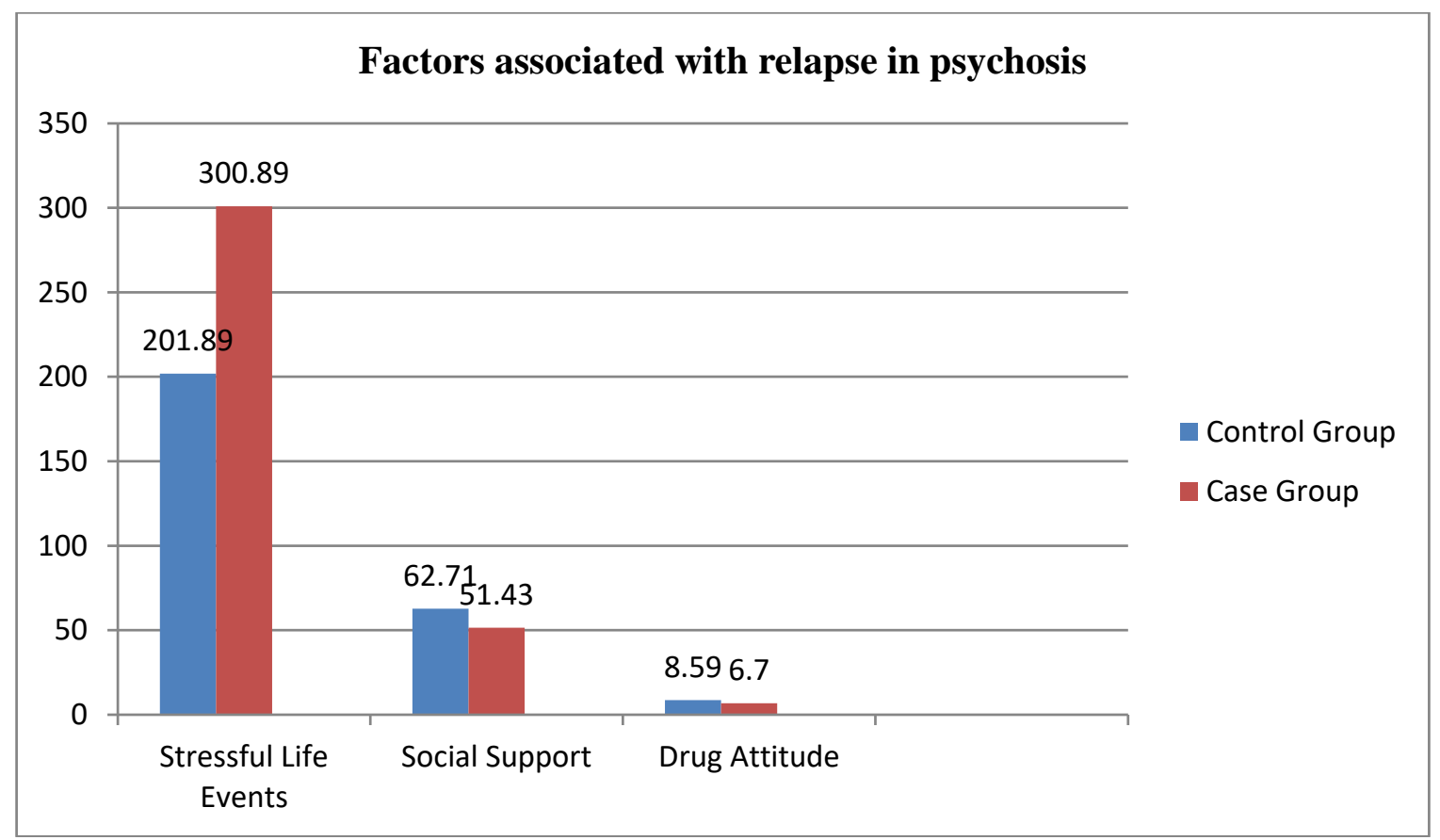

Figure 1. Mean score of factors associated with relapse in psychosis among patients with psychosis 
Table 3:Perceived social support of Case and Control groups, $\mathrm{N}=140$

\begin{tabular}{|c|c|c|c|c|c|c|c|}
\hline \multirow[t]{2}{*}{ Perceived Social support } & \multicolumn{2}{|c|}{$\begin{array}{l}\text { Case Group } \\
n=70\end{array}$} & \multicolumn{2}{|c|}{$\begin{array}{l}\text { Control } \\
\text { Group } \\
\text { n=70 }\end{array}$} & \multirow[t]{2}{*}{$\begin{array}{l}\text { Odds } \\
\text { Ratio }\end{array}$} & \multirow[t]{2}{*}{$95 \%$ CI } & \multirow[t]{2}{*}{$\begin{array}{l}\text { p- } \\
\text { value* }\end{array}$} \\
\hline & No & $\%$ & No & $\%$ & & & \\
\hline \multicolumn{8}{|l|}{ Family support } \\
\hline Low to moderate support & 61 & 87.1 & 51 & 72.9 & \multirow[t]{2}{*}{.109} & \multirow[t]{2}{*}{$.036-.335$} & \multirow[t]{2}{*}{.000} \\
\hline High friends support & 9 & 12.9 & 19 & 27.1 & & & \\
\hline \multicolumn{8}{|l|}{ Friends support } \\
\hline Low to moderate support & 25 & 35.7 & 4 & 5.71 & \multirow[t]{2}{*}{.396} & \multirow[t]{2}{*}{$.165-.951$} & \multirow[t]{2}{*}{.028} \\
\hline High family support & 45 & 64.3 & 66 & 94.3 & & & \\
\hline \multicolumn{8}{|l|}{ Significant others support } \\
\hline Low to moderate support & 28 & 40 & 5 & 7.1 & \multirow[t]{2}{*}{.115} & \multirow[t]{2}{*}{$.041-.322$} & \multirow[t]{2}{*}{.000} \\
\hline $\begin{array}{ccc}\text { High } & \text { significant } & \text { others } \\
\text { support }\end{array}$ & 42 & 60 & 65 & 92.9 & & & \\
\hline
\end{tabular}

$* P$ value set as $<0.05$

Table 4: Factors associated with relapse in psychosis among Relapse and Non-relapse group, $\mathrm{N}=140$

\begin{tabular}{|c|c|c|c|c|c|c|c|}
\hline \multirow[t]{2}{*}{ Factors of relapse } & \multicolumn{2}{|c|}{$\begin{array}{l}\text { Case Group } \\
\mathbf{n}=70\end{array}$} & \multicolumn{2}{|c|}{$\begin{array}{l}\text { Control } \\
\text { Group } \\
\text { n=70 }\end{array}$} & \multirow[t]{2}{*}{$\begin{array}{l}\text { Odds } \\
\text { Ratio }\end{array}$} & \multirow[t]{2}{*}{$95 \% \mathrm{CI}$} & \multirow[t]{2}{*}{ p-value } \\
\hline & No & $\%$ & No & $\%$ & & & \\
\hline \multicolumn{8}{|l|}{ Attitude towards drugs } \\
\hline Unfavourable attitude & 41 & 58.6 & 11 & 15.7 & \multirow[t]{2}{*}{.132} & \multirow[t]{2}{*}{$.059-.294$} & \multirow[t]{2}{*}{.000} \\
\hline Favourable attitude & 29 & 41.4 & 59 & 84.3 & & & \\
\hline \multicolumn{8}{|l|}{ Stressful life events } \\
\hline Less stressful life events & 33 & 47.1 & 50 & 71.4 & \multirow[t]{2}{*}{2.803} & \multirow[t]{2}{*}{$1.393-5.641$} & \multirow[t]{2}{*}{.003} \\
\hline More stressful life events & 37 & 52.9 & 20 & 28.6 & & & \\
\hline \multicolumn{8}{|l|}{ Perceived Social support } \\
\hline Low to moderate support & 56 & 80 & 43 & 61.4 & \multirow[t]{2}{*}{.398} & \multirow[t]{2}{*}{$.187-.850$} & \multirow[t]{2}{*}{.013} \\
\hline High social support & 14 & 20 & 27 & 38.6 & & & \\
\hline
\end{tabular}

*P value set as $<0.05$

\section{RESULTS}

The mean age of the respondents was $33.51 \pm 10.94$ in cases and $35.79 \pm 11.12$ in the control group. About $54.3 \%$ in case and $65.7 \%$ in control group were male and $48.6 \%$ in case and $52.9 \%$ in control group were married. Regarding education, $25.7 \%$ in cases had secondary school education and control group $30 \%$ had primary school education with about $1 / 3^{\text {rd }}$ of the respondents were jobless in both the groups. About 52.9\% in case and $74.3 \%$ in control group had a family income less than Rs. 5000. Considering the living details, $98.6 \%$ in the case and $97.1 \%$ in control were living with their family. In relation to locality, $51.4 \%$ of the participants in case and 52.9\% in control group were from urban background. Regarding the State of residence, $61.4 \%$ in case and $84.3 \%$ in control group were from Tamil Nadu (Table 1). About $65.7 \%$ in case and $71.4 \%$ in control group were diagnosed to have schizophrenia and $42.9 \%$ in case and $37.1 \%$ in control group had the onset of illness at the age between 21-30 years with the mean age of onset of illness was $26.73 \pm 9.04$ and $30.77 \pm 9.78$ years.
Considering the duration of illness, $47.1 \%$ in the case and $62.9 \%$ in control group had one to five years duration of illness with mean duration $6.80 \pm 6.01$ and $5.00 \pm 5.43$ years (Table 2). Mean score \pm SD of stressful life events in case was $300.88 \pm 193.62$ and $201.88 \pm 119.93$ in control group; social support in case group was $51.43 \pm 12.35$ and $62.76 \pm 9.76$ in control; drug attitude in case group was $6.70 \pm 1.95$ and $8.58 \pm 1.16$ in control group (Figure 1).

Low to moderate family support was greater in case $87.1 \%$ compared to $72.9 \%$ in control group and high friends support was 94.3\% in control group and $64.3 \%$ in case group. High significant others support was $92.9 \%$ in control group and $60 \%$ in case group. There were significant differences in family, friends and significant others support with relapse in psychosis in between case and control groups $(\mathrm{OR}=.109,95 \% \mathrm{CI}=.036-.335, \mathrm{p}=.000$; $\mathrm{OR}=.396,95 \% \mathrm{CI}=.165-.951, \mathrm{p}=.028 ;$ and $\mathrm{OR}=.115,95 \%$ $\mathrm{CI}=.041-.322, \mathrm{p}=.000)$. It shows case group had low family, friends and significant others support and psychotic patients have high social support, they less likely to have relapsed (Table 3).

Unfavourable attitude towards drug intake were more $(58.6 \%)$ in case group as compared to control group $15.7 \%$. 
Regarding stressful life events, more stressful life events were more $(52.9 \%)$ in case group than in control group $28.6 \%$ and low to moderate social support were more $(80 \%)$ in cases in comparison to control group $61.4 \%$. Researcher found that there were significant differences in drug attitude, perceived stressful life events and social support in between cases and controls, $\mathrm{p}=<.05$. Favourable attitude towards drug intake $(\mathrm{OR}=.132,95 \%$ $\mathrm{CI}=.059-.294)$, more stressful life events $(\mathrm{OR}=2.803,95 \%$ $\mathrm{CI}=.1 .393-5.641)$ and high social support $(\mathrm{OR}=.398,95 \%$ $\mathrm{CI}=.187-.850)$ in between cases and controls were the significant factors of the relapse in patients with psychosis. It reveals cases had less favourable attitude towards drug intake, more stressful life events and less high social support in comparison to control group (Table 4).

\section{DISCUSSION}

This study was designed as a hospital-based case control study aimed to analyse the factors associated with relapse in psychosis among patients with psychosis in a tertiary hospital of Tamil Nadu, India.

In present study, mean age of the participants in cases was $33.51 \pm 10.94$ and $35.79 \pm 11.12$ in control group which was higher to the cross-sectional study conducted among the one hundred relapse and one hundred non-relapse cases of schizophrenia attended in three psychiatry outpatient departments of Dhaka, Bangladesh showed $28.7 \pm 7.4$ in relapse and $27.9 \pm 6.0$ in nonrelapse group. ${ }^{[28]}$

This study findings revealed that the low to moderate family support was greater in case $87.1 \%$ compared to $72.9 \%$ in control group and high friends support was $94.3 \%$ in control group and $64.3 \%$ in case group. High significant others support was $92.9 \%$ in control group and $60 \%$ in case group. There were significant differences in family, friends and significant others support with relapse in psychosis in between case and control groups $(\mathrm{OR}=.109,95 \% \mathrm{CI}=.036-.335, \mathrm{p}=.000 ; \mathrm{OR}=.396,95 \%$ $\mathrm{CI}=.165-.951, \mathrm{p}=.028$; and $\mathrm{OR}=.115,95 \% \mathrm{CI}=.041-.322, \mathrm{p}=.000)$. It shows case group had significantly low family/friends/significant others support and if psychotic patients have high social support; they are less likely to have relapsed. This study finding was contrasted to a cross sectional study conducted among352 patients with schizophrenia in northern, central, and southern regions of Thailand which showed the finding of family support was at a moderate level in both psychotic relapse and nonrelapse groups and thus there was no significant difference with $\mathrm{p}=0.35$. $^{[29]}$

This study findings regarding attitude towards drug showed that unfavourable attitude towards drug intake were more $(58.6 \%)$ in case group as compared to control group was $15.7 \%$. There was a significant difference in attitude towards drug intake with relapse in psychosis between the two groups $(\mathrm{OR}=.132$, 95\% CI .059$.294, \mathrm{p}=.000)$. It means unfavourable attitude towards drug intake leads to poor adherence to treatment and increases the risk of relapse in patients with psychosis. This study finding is similar to a cross sectional study conducted among 386 patients with psychotic disorder in Jimma University Specialized Hospital, Southern Ethiopia which showed the odds of developing psychotic relapse among patients compliant to medication was $69 \%$ lower than that of patients with not compliant to medications $(\mathrm{OR}=.310$,
95\% CI $=0.12-0.80) .{ }^{[14]}$ Another cross-sectional study conducted among one hundred relapse and one hundred non-relapse cases of schizophrenia who attended three psychiatry outpatient departments of Dhaka, Bangladesh presents the similar findings where non-compliance was higher among the relapse group $(80.0 \%)$ than the non-relapse group $(14 \%)$ and was statistically significant $\mathrm{p}=<.001 .{ }^{[28]}$ in addition, similar finding was found in the study conducted among 217 schizophrenic patients in Johannesburg that showed that two-third of the study population were poor adherent to treatment in relapse with $\mathrm{p}=<.001 .{ }^{[10]}$ furthermore, in a retrospective observational study conducted among 876 people of Republic of China also revealed similar findings in which $30 \%$ of respondents had negative attitudes towards medicine with 2.5 times more relapse than adherent to medicine $54.5 \%$ versus $20.7 \%$ with $(\mathrm{OR}=4.602$, $\mathrm{p}=<.001){ }^{[30]}$

Regarding stressful life events in this study, more stressful life events were higher $(52.9 \%)$ in case group than in control group $28.6 \%$ with a significant difference in between two groups $(\mathrm{OR}=2.803,95 \% \mathrm{CI}=.1 .393-5.641 \mathrm{p}=.003)$. This study finding was similar to findings of a cross sectional study conducted among the one hundred relapse and one hundred non-relapse cases of schizophrenia attended in three psychiatry outpatient departments of Dhaka, Bangladesh showed that occurrence of stressful life events was $10 \%$ in relapse and $1 \%$ in non-relapse cases which was statistically significant with $\mathrm{p}=<.001 .^{[28]}$

Present study findings revealed that low to moderate social support were higher $(80.0 \%)$ in relapse group in comparison to non-relapse group (61.4\%) with a significant difference in perceived social support in psychosis between two groups $(\mathrm{OR}=.398,95 \% \mathrm{CI}=.187-.850, \mathrm{p}=.013)$. It means lower social support is one of the factors associated with relapse in patients with psychosis. This study findings are consistency with a cross sectional study conducted among 386 patients with psychotic disorder in Jimma University Specialized Hospital, Southern Ethiopia showed the odds of developing psychotic relapse among patients having high score on social support was $48 \%$ lower than that of patients who were having low social support $(\mathrm{OR}=.52,95 \%$ $\mathrm{CI}=.28, .95)^{[14]} \mathrm{A}$ study conducted in Germany on predictors of medication adherence among 127 patients with severe psychiatric disorders revealed having social support significantly helped to decrease relapse with $(\mathrm{OR}=1.02, \mathrm{p}=<.001) .{ }^{[31]} \mathrm{A}$ qualitative study conducted, involving in-depth interviews of seven people with schizophrenia and their seven family caregivers in Tanzania perceived no adherence to antipsychotic medication as a leading risk factor of relapse; other risks included poor family support and stressful life events. Family support and adherence to antipsychotic medication were viewed as protective factors. ${ }^{[32]}$

\section{CONCLUSION}

Based on the findings of the study, majority of patients in the relapse group were having unfavourable attitude towards drug intake, more stressful life events and lower perceived social support. There was strong statistically significant association between relapse and attitude towards drug intake, stressful life events and perceived social support. It suggests that there is a need to take consideration to prevent relapse in psychosis. Psychiatric nurse plays an important role in relapse prevention. Assessment of 
drug attitude, life events, and perceived social support during nursing intervention and discharge time might be helpful for the prevention of relapse.

\section{LIMITATIIONS}

Because of the nature of cross-sectional study causality association could not be made. Also, purposive sampling technique restricts the generalizability of the findings.

\section{ACKNOWLEDGMENT}

I would like to express my heartfelt gratitude to all the respondents for their participation and cooperation in this study. Similarly, I would like to express my sincere thanks to Dr. Bimala Panthee for necessary help in statistical analysis as well as manuscript writing and Dr. Priscilla Samson for necessary help in manuscript writing.

\section{Conflict of interest}

None

\section{Funding}

None

\section{REFERENCES}

[1] Lalitha K. Mental health and psychiatric nursing. Bangalore: Gajanana book publishers \& distributors, 2004, Classifications of mental illness, p.67

[2] Gbiri CA, Badru FA, Ladapo HT, Gbiri AA. Socio-economic correlates of relapsed patients admitted in a Nigerian mental health institution. Int $\mathbf{J}$ Psychiatry Clin Pract. 2011; 15(1):19-26. doi: 10.3109/13651501.2010.506954

[3] Capdevielle D, Boulenger JP, Villebram D, Ritchie K. Schizophrenia patients' length of stay: Mental health care implications and medicoeconomic consequences. Encéphale. 2009; 35(4):394-399. doi: 10.1016/j.encep.2008.11.005.

[4] World Health Organization and World Organization of Family Doctors. Integrating mental health into primary care:A global perspective. Singapore: WHO Press.2008.

[5] Chaurotia VK, Verma KK, Baniya GC. A study of psychosocial factorsrelated with relapse in schizophrenia. IOSR-JDMS. 2016; 15(4):2634. Available from: www.iosrjournals.org.

[6] Rickwood D. Pathways of recovery: Preventing further episodes of mental illness (Monograph). Commonwealth of Australia Canberra.2006.Available from: https://researchprofiles.canberra.edu.au/en/publications/pathways-ofrecovery-preventing-further-episodes-of-mental-illnes

[7] World Health Organization. Schizophrenia [Internet]. 2019 [cited 2020 January 19]. Available from: https:// www.who.int/news-room/factsheets/detail/schizophrenia.

[8] Alvarez-Jimenez M, Priede A, Hetrick SE, Bendall S, Killackey E, Parker $\mathrm{AG}$, et al. Risk factors for relapse following treatment for first-episode psychosis: A systematic review and meta-analysis of longitudinal studies. Schizophr Res. 2012; 139(1-3): 116-28. doi: 10.1016/j.schres.2012.05.007.

[9] Galletly C, Castle D, Dark F, Humberstone V, Jablensky A, Killackey E, et al. Royal Australian and New Zealand College of Psychiatrists clinical practice guidelines for the management of schizophrenia and related disorders. Aust N Z J Psychiatry. 2016;50(5):1-117. doi: 10.1177/ 0004867416641195

[10] Kazadi, NJB, Moosa, MYH, Jeenah, FY. Factors associated with relapse in Schizophrenia. S. Afr. j. psyc.2008;14(2):52-62.doi:10.4102/sajpsychiatry. v14i2.158

[11] Sousa SA, Frazier R. A nursing tool for adherence and recovery in psychosis. J PsychosocNursMent Health Serv. 2004; 42(3):28-36. Available from: https://pubmed.ncbi.nlm.nih.gov/15068164/

This publication is licensed under Creative Commons Attribution CC BY.

http://dx.doi.org/10.29322/IJSRP.11.09.2021.p11759
[12] Scott J, Pope M. Non adherence with mood stabilizers prevalence and predictors. J Clin Psychiatry; 63(5):384-390.doi: 10.4088/jcp. v63n0502.

[13] Roe D, Chopra M, Wagner B, Katz G, Rudnick A. The emerging self in conceptualizing and treating mental illness. J PsychosocNursMent Health Serv. 2004;42(2):32-40. doi: 10.3928/02793695-20040201-06

[14] Fikreyesus M, Feyissa GT, Soboka M. Psychotic relapse and associated factors among patients attending health services in Southwest Ethiopia: A cross sectional study. BMC Psychiatry. 2016; 16: 354. doi: 10.1186/s12888016-1076-2.

[15] Owens DC, Johnston EC, Miller P, Macmillan JF, Crow TJ. Duration of untreated illness and outcome in schizophrenia: Test of predictions in relation to relapse risk. $\mathrm{Br} \mathrm{J}$ Psychiatry. 2010;196(4):296-301. doi: 10.1192/bjp.bp.109.067694.

[16] Hussein HA. Impact of Life Events on the Relapse of Schizophrenic Patients. Journal of Education and Practice. Vol.7, No.10, 2016; 7(10):40-47 www.iiste.org

[17] Gautam S, Aggrawal R, Sharma H. Election - A stressful life event. Indian J. Psychiatry. 1997;39(4):329332.https://pubmed.ncbi.nlm.nih.gov/21584102/

[18] Hultman CM,Wieselgren IM,Ohman A. Relationships between social support, social coping and life events in the relapse of schizophrenic patients. Scand J Psychol. 1997; 38(1):3-13.doi: 10.1111/1467-9450.00002.

[19] Jingbo X, Weifeng M, Lingzhi L,Ying S, Hongyan Z. High relapse rate and poor medication adherence in the Chinese population with schizophrenia: Results from an observational survey in the People's Republic of China. Neuropsychiatr Dis Treat. 2015; 11:1161-1167.doi: 10.2147/NDT.S72367

[20] Narayanaswamy JC, Shanmugam VH, Raveendranathan D, Viswanath B, Muralidharan K. Short-term diagnostic stability of acute psychosis: Data from a tertiary care psychiatric center in South India. Indian J Psychol Med. 2012; 34:176-87.doi: 10.4103/0253-7176.101797.

[21] WiersmaD, NienhulsFJ, SlooffC.J, GielR. Natural course of schizophrenic disorders: A 15 - year follow-up of a Dutch incidence cohort. Schizophr. Bull. 1998; 24:75-85. doi: 10.1093/oxfordjournals.schbul.a033315.

[22] Nielsen RE, Lindstrom E, Nielsen J, Levander S.DAI-10 is as good as DAI30 in schizophrenia. Eur Neuropsychopharmacol. 2012; 22:747750.doi:10.1016/j.euroneuro.2012.02.008.

[23] Hogan TP, Awad AG, Eastwood R. A self-report scale predictive of drug compliance in schizophrenics: Reliability and discriminative validity. Psychol Med. 1983; 13:177-183.doi: 10.1017/s0033291700050182.

[24] Shariati B, Shabani A, Ariana-Kia E, Ahmadzad-Asl, Alavi K, Behbahan $\mathrm{ZM}$, et al. Drug attitude inventory in patients with bipolar disorder: Psychometric properties. Iran J Psychiatry Behav Sci. 2018;12(3): e9831.doi: 10.5812/ijpbs.9831.

[25] Singh G, Kaur D, Kaur H. Presumptive stressful life events scale (PSLES) A new stressful life events scale for use in India. Indian J. Psychiatry. 1984; 26(2):107-114. Available from https://pubmed.ncbi.nlm.nih.gov/21965968/

[26] Zimet GD, Dahlem NW, Zimet SG, Farley GK. The Multidimensional Scale of Perceived Social Support. J Pers Assess.1988; 52(1):30-41. doi:10.1207/s15327752jpa5201_2

[27] Wongpakaran T, Wongpakaran N, Ruktrakul R. Reliability and validity of the Multidimensional Scale of Perceived Social Support (MSPSS): Thai Version. Clin PractEpidemiolMent Health. 2011; 7:161-166.doi: 10.2174/1745017901107010161

[28] Haque AKM, KaziMostofa Kamal AHM,De Laila Z., Laila L, Ahmed H, Khan N. Factors associated with relapse of schizophrenia. Bang J Psychiatry. 2018; 29(2):59-63. doi: 10.3329/bjpsy. v29i2.37851.

[29] Pothimas N, Tungpunkorn P, Chanprasit C, Kitsumban V. A cross sectional study of factors predicting relapse in people with schizophrenia. Pacific Rim Int J Nurs Res 2020;24(4): 448-459.Available from: https://he02.tcithaijo.org/index.php/PRIJNR/article/view/226797/166904

[30] Xiao J, Mi W, Li L, Shi Y, Zhang H. High relapse rate and poor medication adherence in the Chinese population with schizophrenia: Results from an observational survey in the people's republic China.Neuropsychiatr Dis Treat. 2015; 11:1161-1167.doi: 10.2147/NDT.S72367.

[31] Stentzel U, Van den Berg N, Lara NS, Schwaneberg T, Franziska R, Jens ML, et al. Predictors of medication adherence among patients with severe psychiatric disorders: findings from the baseline assessment of a randomized controlled trial (Tecla). BMC Psychiatry. 2018; 18:155. doi:10.1186/s12888$018-1737-4$ 
[32] Sariah AE, Outwater AH, Khadija IYM, Risk and protective factors for relapse among Individuals with Schizophrenia: A qualitative study in Dar es Salaam, Tanzania. BMC Psychiatry.2014; 14:240. doi:10.1186/s12888-014$0240-9$

\section{AUTHORS}

First Author - Shobha Laxmi Bajracharya, Associate Professor, Patan Academy of Health Sciences, School of Nursing and
Midwifery, Lalitpur Nursing Campus, Sanepa, Lalitpur, Nepal., POB 21885, Institute: Tel/Fax: +977-1-5905720,

Email:Inc@pahs.edu.np, Researcher: Tel: +977-9841513027, Researcher's Email: shobhalaxmibajracharya@pahs.edu.np, Alternate email address: shobhabajracharya32@gmail.com 